\title{
The empirical-phenomenological research framework: Reflecting on its use
}

\author{
Martin Christensen * \\ School of Nursing, Queensland University of Technology, Brisbane, Australia
}

Received: April 3, 2017

Accepted: May 23, 2017

Online Published: July 30, 2017

DOI: $10.5430 /$ jnep.v7n12p81

URL: https://doi.org/10.5430/jnep.v7n12p81

\begin{abstract}
Background and objective: Descriptive phenomenology when used within the tradition of Husserl offers the qualitative researcher a unique perspective into the lived experience of the phenomena in question. Methods of data analysis are often seen as the theoretical framework for which these studies are then focused. However, what is not realised is that the data analysis tool is merely that a tool for which to delineate the individual narratives. What is often missing is a research framework for which to structure the actual study. Therefore, the aim of this paper is to offer a reflective account of how the empirical-phenomenological framework shaped and informed a descriptive phenomenological study looking at the lived experience of male nursing students as they journey though the under-graduate nursing programme.

Methods: A reflective narrative was used to examine and explore how the empirical-phenomenological framework can be used to support method construction within a descriptive phenomenological study.

Results and conclusions: The empirical-phenomenological research framework aims to provide a practical method for understanding and valuing the range and depth of descriptive phenomenology, in particular the lived experience. Used in combination with specific phenomenological data analysis models the empirical-phenomenological framework is structured to support the qualitative research process.
\end{abstract}

Key Words: Phenomenology, Descriptive phenomenology, Empirical-phenomenological framework

\section{INTRODUCTION}

Descriptive scientific phenomenology can be thought of as a method which aims to describe concrete situations of every day lived experience. ${ }^{[1]}$ It differs significantly from the philosophical method particularly how the natural attitude and the phenomenological reduction aim to explain the phenomena in question. The aim of this paper is to reflect on the experiences of using Todres and Holloways ${ }^{[2]}$ empirical-phenomenological framework as a means to frame descriptive phenomenological research. In addition discussion will be provided as to how this framework provides some insight as to how it may shape suppositions and thoughts about descriptive phenomenology from a research perspective. Throughout there is reference to the author's study which was a descriptive phenomenological study of the lived experience of male nursing students. However, it is not a discussion of the study itself.

\section{EMPIRICAL-PHENOMENOLOGICAL FRAME- WORK-A REFLECTION}

In contemplating the philosophical approach that would be used for this study this author was drawn more and

\footnotetext{
*Correspondence: Martin Christensen; Email: martin.christensen@qut.edu.au; Address: School of Nursing, Queensland University of Technology, Brisbane, Australia.
} 
more towards descriptive phenomenology in the tradition of Husserl. While there are any number frameworks for which to analyse the data in descriptive phenomenology such as Colaizzi ${ }^{[3]}$ and Giorgi, ${ }^{[1]}$ it was Giorgi' ${ }^{[1]}$ approach that was used. However while Giorgi's ${ }^{[1]}$ framework is predominately used in the data analysis stage, there is very little from which to structure the overall methodology of the study itself, in other words something to underpin its guiding principles, hence the decision to use Todres and Holloway's ${ }^{[2]}$ empirical-phenomenological research framework for which to frame this study. The study used Giorgi's four-step scientific phenomenological analysis (see Figure 1) encompassed within stage three of Todres and Holloway ${ }^{[2]}$ empirical-phenomenological research framework because this was seen this as being the best fit for what the study wanted to achieve.

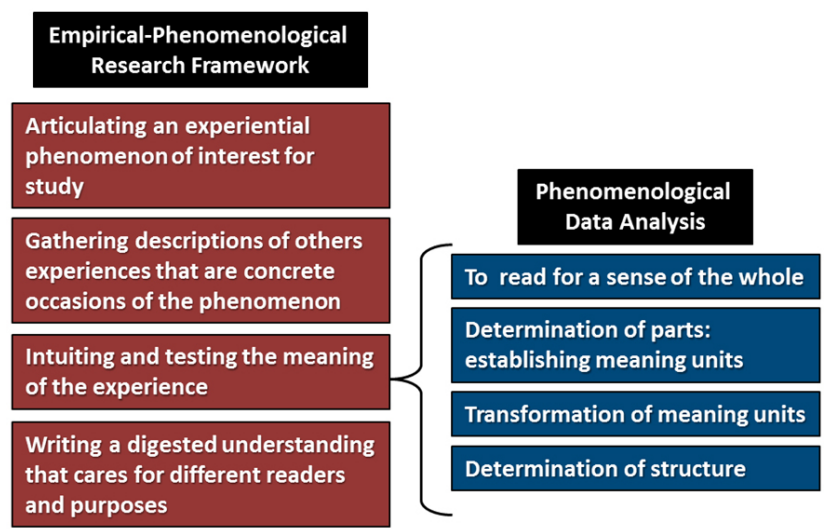

Figure 1. Giorgi's (1985) 4-step method to Phenomenological Data Analysis encompassed within Todres and Holloway's (2004) Empirical-Phenomenological Framework

The challenge of this approach is that offers the researcher an "authentic productive linguistic gathering" in the life-world experiences of the participants and together brings an "alive- ness" to their descriptions which enables the reader to engage in and with the dialogue. ${ }^{[2]}$ But importantly it allows for the description of a process that brings new meaning to the phenomena, how the phenomena came into being and how the phenomena was sought and gathered (see Table 1).

\section{Articulating an experiential Phe- NOMENON OF INTEREST FOR STUDY ${ }^{[2]}$}

In the first stage of the Todres and Holloway's ${ }^{[2]}$ empiricalphenomenological research framework is articulating an experiential phenomenon of interest. It is here that the researcher explores and acknowledges their initial interest in the subject. As Todres and Holloway's (p.84) ${ }^{[2]}$ explain:

We acknowledge our human embeddedness and participation in experiential life. This includes a sensitivity to our own historical, professional and community contexts.

The author's interest in men as nurses is a new phenomenon. Even whilst "training" to be a nurse, there was very little consideration as to the gender-divide or indeed the gender-role confusion that has been attributed to being a male nurse. ${ }^{[4]}$ Now as a nursing academic the gender differences are often forgotten when facing a lecture hall of nursing students; the view is simply see nursing students and not male and female nursing students. It is this notable absence of the difference between men and women within nursing that became the beginning understanding. Reviewing the literature around the nature of men in nursing has led to the belief that there is often discrimination; not meant maliciously but at times a protective cloak to shield the individual and the profession from disrepute. Of course there are those male nurses who take advantage of this and not necessarily in a Machiavellian way, but as a means to further their career prospects as well as the financial gain that comes with promotion.

Table 1. Defining the authentic productive linguistic gathering (Todres \& Holloway, 2004; 94-95)

\begin{tabular}{|ll|}
\hline Authentic & In that the enquiry is based on life world descriptions \\
Productive & $\begin{array}{l}\text { In that the findings are expressed in a way that allows readers themselves to engage in dialogue with the } \\
\text { "aliveness" of the phenomenon that the words point to }\end{array}$ \\
Linguistics & $\begin{array}{l}\text { In that the presentation in descriptive phenomenology is in the form of explicit language } \\
\text { In that the expression of findings is not considered absolute not merely arbitrary. Instead the findings are } \\
\text { relevant and truthful offerings by the phenomenological researcher that carry transferable insights as potential } \\
\text { "platforms" for others }\end{array}$
\end{tabular}

Reflecting on the original proposal to this study it was noted that much had been written about the disadvantages that men face within the profession; the struggles and barriers for acceptance for example, ${ }^{[5]}$ but little about the celebrations of male nursing, the very nature or the lived experience of being a male nurse. Citing Todres and Holloway (p.84), ${ }^{[2]}$ 
"our beginning understandings about an area of interest are intimately formed by significances of which we are a part", and therefore there was a need to understand the:

- The lived experience of under-graduate male nursing students;

- The purpose of nursing for men.

Therefore it is this reflecting on the ground that brings the life-world of the male nursing student to the fore-ground of knowledge and understanding. While there are barriers it is important to be better informed about the quality of life issues even within an educational setting because it is about exploring the nature of the happening or meaning of experiences that describe the journey of nursing education for the male nursing student.

\section{GATHERING DESCRIPTIONS OF OTHERS EXPERIENCES THAT ARE CONCRETE OC- CASIONS OF THIS PHENOMENON}

This type of study commonly requires the researcherparticipant to be engaged in an open dialogue in order to reproduce a detailed description of the phenomena in question. The individual one-to-one interviews were appropriate for this research study because this study wanted to explore the lived experience of being a male nursing student. As Sorrell and Redmond (p.1120) ${ }^{[6]}$ suggested, the purpose of the phenomenological interview is:

“... not to explain, predict or generate theory, but to understand shared meanings by drawing from the respondent a vivid picture of the lived experience, complete with the richness of detail and context that shape the experience."

\section{Articulating an "experience near" research question} However, as Todres and Holloway ${ }^{[2]}$ point out inviting participants to describe their lived experiences of under-graduate nursing education as men, it is often necessary to formulate an "experience near" question to elucidate the phenomenon in question. Indeed, phenomenological questions are those that are formed from the basic constituents of the meaning or essence of something that people live through, how these meanings are then formed, unfold, or even evolve over time. ${ }^{[7,8]}$

Given the nature of a descriptive phenomenological study it is challenging to identify a suitable experience near question based on Giorgi's ${ }^{[9]}$ questions. In the context of this study there was an awareness of the previous work that had been undertaken into understanding the experiences of men in nursing, especially those in the under-graduate programme. What

Published by Sciedu Press had transpired as the written transcripts and the recorded interviews were reflected upon, was how easy it was to fall into what Giorgi ${ }^{[10]}$ calls the "presuppositionless description" - description that avoids any form of scientific explanation but relies on naïve everyday language. But more importantly there is a need to remember the cardinal rule of descriptive phenomenology - the phenomenological reduction (bracketing). Indeed, in the context of this study, it is being mindful of not allowing individual preconceived experiences of what it meant to be a male nursing student to pervade these interviews. Although, LeVasseur ${ }^{[11]}$ contends that when our interest or curiosity in the subject under discussion arises, we naturally or instinctively bracket any form of prior understanding so that we better appreciate the new insights that are formed. Moreover, Dahlberg et al., ${ }^{[12]}$ suggests that it is almost impossible to fully bracket all pre-understanding of a given topic especially in the life-world. Therefore being able to develop open-ended "phenomenological questions" that allows for a disengagement from personal previous experiences is crucial to remain faithful to the phenomena under investigation. Being reminded, however, of what Lowes and Prowse ${ }^{[13]}$ see as the enthusiasm for the topic invariably brings with it the "baggage" of presuppositions and personal insights. This may be appropriate if there is an adherence to the Husserlian philosophy of phenomenology, because it would be personal experience alone that would be the focus of the inquiry.

\section{INTUITING AND TESTING THE MEANINGS OF THE EXPERIENCE}

In descriptive phenomenology, as already mentioned, the wholeness of the lived experience can never be fully elucidated in mere transcriptive form. The qualitative and phenomenological nature of this particular study was aiming to what Todres and Holloway ${ }^{[2]}$ refer to as the "moreness" and "thereness" of the lived-experience so as to articulate a transferable meaning of the phenomena in a generalised way. Giorgi ${ }^{[14]}$ proposed a four stage model of descriptive phenomenological analysis that attempts to be faithful and disciplined in expressing and intuiting general meanings of descriptive phenomena by:

(1) Reading a sense of the whole;

(2) Determining and establishing meaning units;

(3) Transforming those meaning units through progressive refinement;

(4) Determining the structure by describing the connected meanings that belong to the experience. 


\subsection{Read for a sense of the whole}

In Giorgi's ${ }^{[14]}$ first part of the scientific method, he suggests that a reading of the whole gives the reader an 'openness' and a global sense to the narrative. Whilst it must be remembered that this is not necessarily the formal in-depth analytical stage of the descriptive method, because the other stages achieve this, it is worth considering that the goal of this stage is to merely develop a general sense of the lived experience. Since there is a sense of holism to descriptive phenomenology, being consciously aware that the data contains forward and backward references is an important consideration given that one without the other makes the experience incomplete. ${ }^{[14]}$ However, this is not simply re-reading the transcript in order to develop meaningful themes as would be seen in other qualitative methods, but to read the transcript while applying the phenomenological reduction - this point Giorgi ${ }^{[14]}$ is very clear should be integral to this stage of the process.

The phenomenological reduction, as is known, is a form of bracketing (in the scientific method) which phenomenological researchers should consciously undertake to disassociate themselves from the phenomena. As a result the "reading for a sense of the whole" takes on a new meaning as the researcher is able to temporarily suspend their own beliefs, experiences and judgements. ${ }^{[15]}$ This author found this process to be beneficial because it was felt at times they were often drawn back to their own experiences of being a nursing student and indeed as a registered nurse, but also being cognisant of Giorgi and Giorgi's (p.249) ${ }^{[16]}$ comments of "what is experienced is understood to be an experiential given to the person experiencing the phenomena". In other words, having an awareness that being able to distinguish the presence of the phenomena (its mode of givenness) and how it actually exists in the person's consciousness and "...take whatever is given to be [the] phenomenon" and as such does not reside within "me" - they are not part of 'my' lived experience. While a researchers experiences are important, it is also important that they do not cloud the narrative's meaning, but to allow a general awareness and grasping of the central tenants of the narrative to evolve and shine through, and yet being mindful that they are not attempting to thematise the data merely attempting to gain a global sense of it. In-depth explanation and description would come later in the process. But for now it is important that a coupling of the interview and the transcripts formed a sense of the "wholeness" to the participants lived experience and not an individual inference of what was being portrayed.

\subsection{Determining and establishing meaning units}

The establishment of natural meaning units is essentially breaking the transcripts into "bite-size chunks" of descrip- tive account. ${ }^{[17]}$ Like the first stage, this stage is not to thematise or interrogate the narrative, but one of partitioning segments of dialogue into something more manageable, but being mindful of the goal, which is the meaning of experiences. The challenge at this stage is that the partitioning process is solely reliant on the researcher's perception, attitude, and lived experience of the narrative being presented and as such there is no objectivity to this stage, but merely a pragmatic approach to supporting and advancing the next stage in the analysis. ${ }^{[14]}$

However, there are some important considerations that needed to be implemented so as not to make the meaning of the meaning units explicitly about the researcher or an over-emphasis of the researchers own lived experiences becoming the centre of the narratives. Therefore, employing the phenomenal reduction throughout is crucial along with what Giorgi ${ }^{[1]}$ describes as the "practice of science" within the "context of discovery" as opposed to the "context of verification". So having first read the transcripts for a sense of the whole, it is important to re-read them to identify a change in the meaning relevant to the phenomenon. These shifts are then marked and partitioned from within the whole so that the entire transcript has now been transformed into a collection of natural meaning units. Being conscious that others following are likely not to identify the same meaning units it is important to remember that at this stage there is no claim to the validity of the narratives or the meaning units, but just identifying items of dialogue that would be transformed by the next stage of the analysis.

Therefore, using the work of Whitting ${ }^{[17]}$ as a guide helps delineate the meaning units into a simple, clear structure of general themes which dominates each transcript. Having completed this part, it is simply a case of cutting each meaning unit and pasting them into a collage of meaning themes from each of the participant's narratives. Once this is complete it is possible to re-read the meaning unit themes with an "openness", which Giorgi ${ }^{[10]}$ describes, and to try to identify a central theme for which to focus on what was being said especially in the manner it was spoken. In addition being aware, as was Whitting ${ }^{[17]}$ that these central themes are only key issues as they related to the meaning unit and not an attempt to interpret their meaning (see Table 1).

\subsection{Transformation of participant's natural attitude ex- pressions (transformation of the meaning units)}

It is the development of the natural meaning units and the identification of central meaning unit themes from the second stage that enables these to be transformed into a more representative description of the participant's lived experiences. Giorgi ${ }^{[14]}$ describes this stage as: 
"... [the start of] interrogating each meaning unit to discover how to express in a more satisfactory way the implications of the life-world description. In other words, for [the] analysis to be fruitful the [narrative] dimension of experience has to be highlighted... detected, drawn out, and elaborated."

Table 2. Exemplar of the development of themes from the natural meaning units

\begin{tabular}{|c|c|c|c|}
\hline Natural Meaning Units & Central Theme & Revelatory Structure & Theme \\
\hline $\begin{array}{l}\text { I'm not here to socialise. It's nice to socialise, but I'm not here } \\
\text { to, that's it. Maybe for some of the girls it is about that. I think a } \\
\text { bit part of it is you need to socialise, whereas for me, no, I need } \\
\text { to get a job done. They socialise, it's nice to talk to people, but I } \\
\text { still need to get my degree and that's - if social life is going to } \\
\text { impact on that, well no, it'll come second every time. }\end{array}$ & Being focused & Striving to succeed & $\begin{array}{l}\text { Nursing is } \\
\text { for Men }\end{array}$ \\
\hline $\begin{array}{l}\text { I think my work ethic comes from just years of experience from } \\
\text { what I've done in being in management roles and that and } \\
\text { knowing what you've got to do. I think it all stems from that and } \\
\text { knowing that I still work, so I have to work hard to do it... it's } \\
\text { me working harder to be accepted. }\end{array}$ & $\begin{array}{l}\text { Have to work } \\
\text { harder to be } \\
\text { accepted }\end{array}$ & Striving to succeed & $\begin{array}{l}\text { Nursing is } \\
\text { for Men }\end{array}$ \\
\hline $\begin{array}{l}\text { I still think some of the students look as us funny for being guys } \\
\text { and particularly an older guy, coming back to nursing. I still } \\
\text { think some of the younger girl students sort of don't accept that } \\
\text { and look at us funny. }\end{array}$ & $\begin{array}{l}\text { Inappropriately } \\
\text { labelled }\end{array}$ & $\begin{array}{l}\text { Feeling the presence of } \\
\text { Gendered Apartheid }\end{array}$ & $\begin{array}{l}\text { Working in a } \\
\text { world of } \\
\text { perceived } \\
\text { negativity }\end{array}$ \\
\hline $\begin{array}{l}\text { Yeah. If it probably wasn't for our facilitator, I would have been } \\
\text { out [of the programme], yeah, definitely, just through purely } \\
\text { why, why you are male nurse, why do you want to be - I’ve } \\
\text { never seen a boy nurse before. }\end{array}$ & $\begin{array}{l}\text { The presence of } \\
\text { questioning eyes }\end{array}$ & $\begin{array}{l}\text { Feeling the presence of } \\
\text { Gendered Apartheid }\end{array}$ & $\begin{array}{l}\text { Working in a } \\
\text { world of } \\
\text { perceived } \\
\text { negativity }\end{array}$ \\
\hline $\begin{array}{l}\text { I was first initially going into paramedics because of the pressure } \\
\text { I felt from other people, especially my friends. It's like, oh you } \\
\text { don't mean nurse; males are paramedics. They're all } \\
\text { construction workers and builders and stuff like that, so } \\
\text { blokey-blokes... why would you do that [be a nurse]? It's like } \\
\text { I'd never wipe someone's bum or anything like that. It's like, } \\
\text { well, you know different. }\end{array}$ & Why be a nurse & Mateship Realigned & $\begin{array}{l}\text { Men are } \\
\text { from Mars }\end{array}$ \\
\hline $\begin{array}{l}\text { I've been told on prac [clinical placement] that the girls are } \\
\text { going to be catty to each other and the female nurses just attack } \\
\text { each other. But they're happy to talk to guys because they know } \\
\text { we really don't get involved in it. Its stupid stuff... they just } \\
\text { attack each other and they hold onto things. They can't let go of } \\
\text { something; if it goes wrong, they've got to hold onto it and that's } \\
\text { what they focus on. }\end{array}$ & $\begin{array}{l}\text { Watching the } \\
\text { cattiness from a } \\
\text { distance }\end{array}$ & $\begin{array}{l}\text { Conscientious Objector } \\
\text { from the margins }\end{array}$ & $\begin{array}{l}\text { Men are } \\
\text { from Mars }\end{array}$ \\
\hline
\end{tabular}

This invariably comes from the researcher and it therefore becomes a challenge of language - the contextualised often cryptic meaning of the student's narrative. Part of this process is employing what Husser ${ }^{[18]}$ referred to as "free imaginative variation" in addition to Giorgi' ${ }^{[1]}$ reflexivity. Having re-read the transcript again and noting the natural meaning units and the central themes, allows the researcher in this case to ask "what is the meaning of men in nursing?" ${ }^{[17]}$ It becomes noticeable that the participant's recollections of their experiences are such that they form distinct descriptions of their everyday language which has meaning for them. Therefore the primary role as the researcher is to articulate these into phenomenon specific language. This process of transformation aims to make explicit language found within the natural meaning units more implicit within the context of the lived experience. This is then situated nicely within the second goal of Giorgi and Giorgi's ${ }^{[16]}$ third stage where to "generalise somewhat so that the analyses are not so situation specific" moves the narrative from the lived concrete experience to a phenomenal experience of clarity 
and specificness. Yet while being able to decipher the narratives into these central themes, it important to repeatedly asked these central themes "what does this tell me about men in nursing". [10] This third phase which Whitting ${ }^{[10]}$ aptly refers to as the development of revelatory themes enables the formation of the final themes that will be analysed and refined in stage four of the Giorgi's ${ }^{[1]}$ framework (see Table $1)$.

\subsection{Determining the structure by describing the con- nected meanings that belong to the experience}

This last stage is a transformation of the meaning units into a constituent structure of male nursing students lived experience. It is by no means the final stage but as Giorgi ${ }^{[14]}$ explains is about the focus of this part of the analysis that is formed from the invariant constituents of the experience in a general perspective. In other words, it is a determination of the constituents of meaning as they apply to the concrete experiences of being a male nursing student as described by the participants which helps the empirical data to be understood in a more methodical fashion. ${ }^{[16]}$ For Giorgi ${ }^{[14]}$ the invariant constituents form the structure of the phenomena under investigation and as such the structure attempts to establish the "typicality" of the phenomenon and the relationship between the inter-linking qualities of the key constituent parts. The overall aim is therefore, to develop a singularly precise structure of the phenomenon. However this is not always possible especially if there is a non-formal intra-structural difference in the constituent parts, in which case several phenomenal structures will appear to exist in unison.

Being aware of this potential problem, ensures that having read and re-read the transcripts as well as having a senses of the whole, that the invariant constituents provides a "typicalness" to the descriptive lived experience of the participant. Importantly, it is also being conscious of the intuited meaning units being described and articulated within the phenomenological reduction so as to reduce the impact of any past experiential influence. This way it ensures that the phenomenological analysis is not solely focused on the essential structure alone, but the inter-relationship of the varied manifestations of the essential identity. ${ }^{[9]}$ What Giorgi ${ }^{[9]}$ means by this is possibly best portrayed more easily in an example:

“... a constituent structure of learning that emerges from descriptive data is a structure identified as "entering a situation with false assumptions". However, this structure has several variations. For example, a false assumption can be due to ignorance, faulty memory, emotional conflict and so on. Obviously the way to correct this false assumption depends upon the nature of the specific variation.

86
Therefore, in the post-structural analysis only general or typical terms are iterated to exemplify the lived experience of the participant as opposed to what is generally thought, which is the universality of the structure. The high specificity of the experiences are often associated with the structure - this is not the case simply because the structure espouses the variant constituents that relate or define directly with the phenomena. ${ }^{[16]}$ As a result "the structure is meant to convey what is truly essential about a series of experiences of the same type".[16]

Being faithful to Giorgi's ${ }^{[14]}$ method means that reporting the structure is presented first in the discussion, followed by the individual variations and constituents. Others have varied this approach inasmuch they have attempted to re-personalise the narrative accounts and contextualise them within a suitable and appropriate theoretical framework mainly as a result of phenomenological reporting pragmatics and narrative complexity. ${ }^{[7]}$ As such the structure is reported secondary with the constituents forming the introductory section to the participant's narrative experiences combined with explicit literary links. Taking this secondary alternative approach meant for Rees, ${ }^{[7]}$ a "descriptive adequacy [that] pays attention to aesthetic dimensions of the participants' experiences in a way that enhances the understanding of the reader". Quoting Todres, ${ }^{[19]}$ Rees (p.78) ${ }^{[7]}$ saw her approach as a means to enriching the "general and typical" texture of the individual experiences to a point which brought credibility to the structure. Using Todres and Holloway's ${ }^{[2]}$ authentic productive linguistic gathering (APLG) appeares attractive when considering an approach to delivering and articulating the general structure of the phenomenon. Like Rees, ${ }^{[7]}$ APLG allows for the reframing of the essential structure of the narratives in a way that does not necessarily bring finality to the overall analysis, but provides a linguistic summation of the narrative experiences and therefore the essences of the phenomena in question. To be reminded of the authentic productive linguistic approach, Todres and Holloway ${ }^{[2]}$ saw the lived phenomenon as "gatherings" as opposed to essences. They use the phenomenon of anger as good example to clarify this approach:

"The phenomenon of anger can be understood in richer ways but each new word or phrase [associated with anger] is not an essence but a gathering. It is a gathering that is instructional rather than summative, as if to say that the explosiveness of anger is named, see how anger in the contexts you are interested in is better understood and leads to further productive understandings and meaningful connections." 
Therefore, as Todres and Holloway ${ }^{[2]}$ suggest the phenomenon has become a "lived platform" and by re-framing essences they have now become a bridge to an authentic productive linguistic gathering.

\section{WRITING A DIGESTED UNDERSTANDING THAT CARES FOR DIFFERENT READERS AND PURPOSES}

The final stage of Todres and Holloways ${ }^{[2]}$ framework for empirical phenomenology encompasses a discussion which concerns both the scientific and communicative aspects of how the phenomenon is presented. The scientific concern is focused on establishing the typicality of the phenomenon and presents it in a coherent, insightful and integrative manner. Whereas the communicative concern considers the reader and the purpose of the study in which 'it may be put' or as Halling ${ }^{[20]}$ suggests the study's ability to accentuate its value to a wider audience.

The scientific approach concerns itself with rigorously expressing the phenomenon in an articulate and consistent way. ${ }^{[2]}$ Moreover, this approach is designed to ensure the descriptive accounts are a credible and valid representation of the participant's experiences, how they are used and transformed into the written word. ${ }^{[7]}$ Phenomenological validity has been initially described as "descriptive adequacy" by Ashworth $^{[21]}$ who suggested that in order for validity to exist within the life-world narrative, the researcher is challenged to ensure the essence or structure of the phenomenon is demonstrable within a given context and is free from the researchers presuppositions and their own life-world experiences. As a result it is important to ensure that the reader has enough rich detail and description of the life-world or lived experience to allow the givenness of the phenomenon to be judged on its open phenomenological attitude. ${ }^{[22]}$ This can be particularly challenging especially where judgements are made about expressing the essences in such a way as to encapsulate the generalness as well as the typicalness of the phenomenon all the while ensuring the variants were fully represented to exemplify fully the life-world experience. ${ }^{\text {[7] }}$

However, the structure cannot always be context free as Rees $^{[7]}$ suggests, instead the structures diversity and fluidity needs to be reinforced in such a way as to reintroduce the aesthetic dimension of the narrative experience and this therefore enables a textural richness to evolve for the reader. In other words:

"Practically, intuiting and expressing invariances across cases means that one is carefully considering the role and status of the variations within the structure. This involves both intuition and logic, as one is holding in one's imagination both the digested understandings, as well as an openness to have this understanding changed by further details."[2]

What Todres and Holloway ${ }^{[2]}$ are referring to is the very nature of how interpreting, describing and reporting the narrative structure so that the readers immersion into and within the description means they were "living" the experience for themselves. This is difficult at times to achieve because merely reading and re-reading the transcripts is not enough. Revisiting the original recordings to pick out nuances of language such as intonation, inflection and cadence of how words, phrases and colloquialisms are used. Pauses and hesitations bring new meaning to the lived experience as to what these might mean not only within the meaning units but the structure as well - in other words would this significantly change the invariant constituents and create greater variance within the identified themes. Therefore it can be decided at this point to re-map the invariant and variant constituents within the themes to ensure they are a true depiction and description of the participant's life-world.

This then allows for the development of the communicative approach. As mentioned above the focus of this stage is to what Rees ${ }^{[7]}$ refers to as "re-peopling" the constituents - the development of rich textural descriptions that make the study easily accessible to the reader. Halling ${ }^{[21]}$ certainly stresses the importance of ensuring phenomenological research being more accessible and useful for its intended audience otherwise it is in danger of becoming a redundant exercise. Indeed Todres and Holloway ${ }^{[2]}$ suggest that an overabundance of presentation styles such as textural, structural-textural or textural-structural synthesis, to cite some examples of previous phenomenological presentation styles, becomes overly repetitive and risks reducing the readers experience and understanding of the phenomenon. Instead, Todres and Holloway (p.91) ${ }^{[2]}$ suggest that self-awareness on the part of the writer "can deepen their aesthetic appeal and engage the 'hearts' of the readers in an invitational rather that an authoritarian manner". In addition being drawn to their closing statement when attempting to reframe the participants experiences within the authentic productive linguistic gathering, they suggest that the role of "the phenomenological researcher [is] as a mediator between the 'voices' and expressions of the research respondents and the broader community of interested people" as opposed to what Halling (p.128) ${ }^{[21]}$ has observed as occurring in some phenomenological studies as being a "disembodied author [writing] about no one in particular”. 


\section{Conclusion}

The experience has been valuable in exploring the participants' narrative especially in bringing a sense of wholeness to their lived experience. The empirical-phenomenological research framework certainly allows for a more focused and succinct structure of the research process and combined with Giorgi's four-step analytical framework provides a comprehensive model. Indeed, being reminded of Todres and Holloway's ${ }^{[2]}$ thoughts of the framework where they state that “... the expression of findings is not considered absolute nor merely arbitrary. Instead, the findings are relevant and truthful offerings... that carry transferable insights as potential platforms for others." Certainly, the practical application of a framework to explore the lived experience provides a disciplined and reflective method for descriptive phenomenology. ${ }^{[2]}$ In terms of its use to a wider qualitative research base is difficult to quantify simply because the framework itself is more specific to descriptive phenomenology. However it is possible for some adaptation to support other qualitative research approaches such as interpretative phenomenology after Heidegger or perhaps narrative and thematic analysis type studies.

\section{CONFLicts OF InTEREST Disclosure}

The author declares that there is no conflict of interest.

\section{REFERENCES}

[1] Giorgi A. Phenomenology and psychological research. Pittsburgh: Duquesne University Press; 1985.

[2] Todres L, Holloway I. Descriptive phenomenology: life-world as evidence. In: Rapport, F. New Qualitative Methodologies in Health and Social Care Research. Routledge, London. 2004. https://doi . org/10.4324/9780203408643_chapter_4

[3] Colaizzi PF. Pyschological research as the phenomenologist views it In, Valle, R.S., King, M., eds, (1978). Existential-Phenomenological Alternatives for Psychology. New York: Oxford University Press 1978.

[4] O’Lynn CE, Tranbarger RE. Men in Nursing: History, Challenges and Opportunities. New York: Springer; 2007. PMid:17998853

[5] Evans J. Men nurses: a historical and feminist perspective. Journal of Advanced Nursing. 2004; 47(3): 321-328. PMid:15238127 https://doi.org/10.1111/j.1365-2648.2004.03096.x

[6] Sorrell J, Redmond GM. Interviews in qualitative nursing research: differing approaches for ethnographic and phenomenological studies. Journal of Advanced Nursing. 1995; 21(6): $1117-$ 1122. PMid:7665776 https ://doi.org/10.1046/j.1365-264 8.1995.21061117.x

[7] Rees KJ. The lived experience of final year student nurses of learning through reflective processes. Unpublished $\mathrm{PhD}$ Thesis, Bournemouth University. 2007.

[8] Churchill SD, Wertz FJ. An introduction to phenomenological research in psychology: historical, conceptual and methodological foundations. In, Schneider, K.J., Pierson, J.F., Bugental, J.F.T., eds. The Handbook of Humanistic Psychology: theory, research and practice 2nd ed. London: Sage: 2014.

[9] Giorgi A. The theory, practice and evaluation of the phenomenological method as a qualitative research procedure. Journal of Phenomenological Psychology. 1997; 28(2): 235-260. https://doi org/10.1163/156916297X00103

[10] Giorgi A. An application of phenomenological method in psychology. In: Giorgi, A., Fischer, W.F., von Eckartsberg, R., eds. Duquesne Studies in Phenomenological Psychology. Pittsburgh: Duquesne University Press; 1975. https ://doi.org/10.5840/dspp197529
[11] LeVasseur J. The problem of bracketing in phenomenology. Qualitative Health Research. 2003; 13(3): 408-420. PMid:12669340 https : //doi .org/10.1177/1049732302250337

[12] Dahlberg K, Drew N, Nystrom M. Reflective Lifeworld Research. Lund, Studentlitteratur. 2001.

[13] Lowes L, Prowse M. Standing outside to interview process? This illusion of objectivity in phenomenological data generation. International Journal of Nursing Studies. 2001; 38(4): 471-480. https : //doi .org/10.1016/S0020-7489(00)00080-8

[14] Giorgi A. The descriptive phenomenological method in psychology: a modified Hollway, W., Jefferson, T.,. Doing Qualitative Research Differently: free association, narrative and the interview method. London: Sage; 2000.

[15] Converse M. Philosophy of phenomenology: how understanding aids research. Nurse Researcher. 2012; 20(1): 28-32. PMid:23061271 https ://doi.org/10.7748/nr2012.09.20.1.28.c9305

[16] Giorgi A, Giorgi B. The Descriptive Phenomenological Psychological Method. In: Camic, P; Rhodes, J. and Yardley, L. Qualitative Research in Psychology. Expanding Perspectives in Methodology and Design. Washington, American Psychological Association. 2003; 243-273 p. https ://doi.org/10.1037/10595-013

[17] Whitting L. Analysis of phenomenological data: personal reflections on Giorgi's method. Nurse Researcher. 2001; 9(2): 60-74.

[18] Husserl E. Logical Investigations, Vol 2. New York, Humanitarian Press; 1970 .

[19] Todres L. Clarifying the life-world" descriptive phenomenology. In Holloway, I., Qualitative Research in Health Care. London: Open University Press; 2005.

[20] Halling S. Making phenomenology accessible to a wider audience. Journal of Phenomenological Pyschology. 2002; 33(1): 19-38. https://doi .org/10.1163/156916202320900400

[21] Ashworth PD. The descriptive adequacy of qualitative findings. The humanistic Psychologist. 2000; 28(1): 138-152. https : //doi.or g/10.1080/08873267.2000.9976987

[22] Finlay L. Debating phenomenological research methods. Phenomenology \& Practice. 2009; 3(1): 6-25. 